\title{
Individual analysis of EEG frequency and band power in mild Alzheimer's disease
}

\author{
Davide V. Moretti ${ }^{\mathrm{a}, \mathrm{c}, \mathrm{d}}$, Claudio Babiloni $^{\mathrm{a}, \mathrm{b}, *}$, Giuliano Binetti $^{\mathrm{b}}$, Emanuele Cassetta ${ }^{\mathrm{c}}$, \\ Gloria Dal Forno $^{\mathrm{d}, \mathrm{h}}$, Florinda Ferreric ${ }^{\mathrm{d}}$, Raffaele Ferri ${ }^{\mathrm{e}}$, Bartolo Lanuzza ${ }^{\mathrm{e}}$, Carlo Miniussi ${ }^{\mathrm{b}}$, \\ Flavio Nobili ${ }^{\mathrm{f}}$, Guido Rodriguez ${ }^{\mathrm{f}}$, Serenella Salinari ${ }^{\mathrm{g}}$, Paolo M. Rossini ${ }^{\mathrm{b}, \mathrm{c}, \mathrm{d}}$ \\ ${ }^{a}$ Dipartimento Fisiologia Umana e Farmacologia, Università degli Studi di Roma 'La Sapienza', P.le Aldo Moro 5, 00185 Rome, Italy \\ ' IRCCS 'S. Giovanni di Dio-F.B.F.', Brescia, Italy \\ ${ }^{\mathrm{c} A . F a . R . ~ O s p e d a l e ~ F B F}$, Isola Tiberina, Rome, Italy \\ ${ }^{\mathrm{d}}$ Neurology, University 'Campus Biomedico', Rome, Italy \\ ${ }^{\mathrm{e}}$ Department of Neurology, Oasi Institute for Research on Mental Retardation and Brain Aging (IRCCS), Troina, Italy \\ ${ }^{\mathrm{f}}$ Division of Clinical Neurophysiology (DIMI), University of Genoa, Genoa, Italy \\ ${ }^{\mathrm{g}}$ Dipartimento di Informatica e Sistemistica, University 'La Sapienza', Rome, Italy \\ ${ }^{\mathrm{h}}$ Department of Neurology, Johns Hopkins University School of Medicine, Baltimore, Maryland, USA
}

Accepted 25 September 2003

\begin{abstract}
Objective: This EEG study investigates the role of the cholinergic system, cortico-cortical connections, and sub-cortical white matter on the relationship between individual EEG frequencies and their relative power bands.

Methods: EEGs were recorded at rest in 30 normal elderly subjects (Nold), 60 mild Alzheimer disease (AD) and 20 vascular dementia (VaD) patients, comparable for Mini Mental State Evaluation scores (MMSE 17-24). Individual EEG frequencies were indexed by the theta/alpha transition frequency (TF) and by the individual alpha frequency (IAF) with power peak in the extended alpha range (5-14 Hz). Relative power was separately computed for delta, theta, alpha1, alpha2, and alpha3 bands, on the basis of the TF and IAF.

Results: Using normal subjects as a reference, VaD patients showed 'slowing' of alpha frequency (TF-IAF) and lower alpha2 power; Mild $\mathrm{AD}$ patients showed lower alpha2 and alpha3 power; delta power was higher in both AD and VaD patients; Theta power was higher only in VaD patients.

Conclusions: Individual analysis of the alpha frequency and power can discriminate mild AD from $\mathrm{VaD}$ and normal elderly subjects.

Significance: This analysis may probe pathophysiological mechanisms causing AD and VaD.

(C) 2003 International Federation of Clinical Neurophysiology. Published by Elsevier Ireland Ltd. All rights reserved.
\end{abstract}

Keywords: Mild Alzheimer's disease; Vascular dementia; Electroencephalography; Alpha rhythm; Delta rhythm

\section{Introduction}

Quantitative analysis of electroencephalographic (EEG) rhythms in resting subjects is a low-cost and potentially useful neurophysiological approach to the study of normal aging and dementia (Gueguen et al., 1991; Maurer and Dierks, 1992; Szelies et al., 1992; Leuchter et al., 1993; Schreiter-Gasser et al., 1993; Bennys et al., 2001). This type of analysis includes the estimation of the power density of

* Corresponding author. Tel.: +39-06-4991-0989; fax: +39-06-49910917.

E-mail address: claudio.babiloni@uniroma1.it (C. Babiloni), http:// hreeg.ifu.uniroma1.it. selected EEG frequency bands (AD; Besthorn et al., 1997; Chiaramonti et al., 1997; Schreiter-Gasser et al., 1994). Compared to normal subjects, Alzheimer's disease (AD) patients are known to have 'slowing of the EEG,' namely through increase of the delta $(0.5-4 \mathrm{~Hz})$ and theta $(4-8 \mathrm{~Hz})$ power, along with decrease of the alpha power $(8-13 \mathrm{~Hz})$. 'Slowing' of the EEG rhythms may be sensitive and correlate to dementia severity and disease progression from the earliest stages (Schreiter-Gasser et al., 1994; Nobili et al., 1999; Ihl et al., 1996). These findings are considered indirect evidence of the fundamental role of cholinergic system in modulating alpha rhythms, given the well-known selective deficit of acetylcholine occurring from the earliest 
stages of AD. However, the typical 'slowing' of EEG rhythms seen in AD (Coben et al., 1983, 1990; Sloan et al., $1995)$ has also been reported in vascular dementia (VaD; Szelies et al., 1992).

The anchor point for a quantitative analysis of the EEG is the alpha rhythm, which dominates the EEG power spectrum in resting normal subjects (Klimesch, 1999). The neural mechanisms of the alpha rhythm have been studied in animal (Steriade and Llinas, 1988) and computational models (Destexhe and Sejnowski, 1996; Suffczynski et al., 2001). Scalp alpha rhythms result from sequences of inhibitory and excitatory post-synaptic potentials at the dendrites of cortical pyramidal neurons. These potentials depend mainly on the influence of near and distant cortical modules (Nunez et al., 2001), as well as on the interactions of excitatory cortico-thalamo-cortical relay fibers and inhibitory thalamic reticular fibers (Lopes da Silva et al., 1980; Suffczynski et al., 2001). An emerging feature of these integrated cortico-cortical and cortico-thalamocortical systems is that, in a resting condition, the higher the number of synchronously active neurons, the higher the amplitude of the alpha rhythm, and the slower the frequency of the alpha power peak (Elul, 1972; Lopes da Silva et al., 1976; Singer, 1993; Pfurtscheller and Lopes da Silva, 1999).

Traditionally, alpha power is evaluated within one or two fixed frequency bands ranging from 8 to $13 \mathrm{~Hz}$. However, reports on age- or disease-related changes in EEG oscillatory activity must be interpreted with caution when broadband analyses are calculated within traditional fixed frequency windows. Studies with individual estimation of EEG frequency (Klimesch, 1999) have indeed shown that a physiological or pathological increase (or decrease) of alpha frequency would result in a shift of alpha peak towards higher (or lower) frequencies. The analysis of fixed frequency band could therefore blur the real alpha peak, masking the age-related modifications or those due to neurological diseases, such as dementia.

There is a body of evidence showing that the analysis of individual EEG frequency bands could reveal additional information about the neurophysiology of brain electrical activity (Kopruner et al., 1984; Niedermayer, 1993; Klimesch, 1999). One of the most important outcomes of this approach is the identification of different sub-bands in the range of the alpha frequency subserving different cognitive functions. These studies, however, have been conducted mainly to define normative values in normal young and elderly populations. Our study aims at extending these results to mild Alzheimer subjects, as compared to normal elderly and vascular demented subjects.

In this study, EEG data were recorded in resting normal subjects (Nold), as well as in mild $\mathrm{AD}$ and $\mathrm{VaD}$ patients. The main focus was to test the impact of the cholinergic system and cortico-cortical connections (known to be impaired in mild AD) and the sub-cortical white matter (damaged in $\mathrm{VaD}$ ) on the relationship between individual EEG frequencies and their relative power bands. To take into account the individual features of the alpha band (Klimesch, 1999), we calculated two individual anchor frequencies obtained, at the EEG spectral profile, by averaging power spectra at all recording electrodes (collapsed spectrum). These frequencies were named theta/alpha transition frequency (TF) and individual alpha frequency (IAF). The IAF was defined as the frequency showing its power peak within the extended alpha range $(5-14 \mathrm{~Hz})$ and the TF was defined as the EEG frequency, slower than the IAF, showing the minimum power. Of note, the estimation of local TF and IAF indices at various electrode sites would disclose regional phenomena of alpha frequency synchronicity. This important issue needs to be addressed in future studies focused on spatial features of EEG rhythms in dementia. In this study, we focused on a relatively quick procedure suitable for clinical application, with the great advantage of requiring minimal data and no differential analysis of the EEG rhythmicity at different scalp sites.

The range of individual EEG frequencies was indexed by the TF and IAF. Relative power band values were computed at individual delta, theta, alpha1, alpha2, and alpha3 bands.

\section{Methods}

\subsection{Subjects}

For the present Italian multi-center study (http://hreeg. ifu.uniroma1.it/Alzheimer.htm), 60 mild AD patients, 20 VaD patients, and 30 Nold subjects were recruited. Local institutional ethics committees approved the study. Informed consent was obtained from all participants or their caregivers, according to the Code of Ethics of the World Medical Association (Declaration of Helsinki) and standards established by the Authors' Institutional Review Boards.

\subsection{Diagnostic criteria}

All patients underwent general medical, neurological, and psychiatric assessments. Patients were rated with a series of standardized diagnostic and severity instruments, including the MMSE (Folstein et al., 1975), the Clinical Dementia Rating Scale (CDRS; Hughes et al., 1982), the Geriatric Depression Scale (GDS, Yesavage et al., 1982), the Hachinski Ischemic Scale (Rosen et al., 1980), and the Instrumental Activities of Daily Living (IADL, Lawton and Brodie, 1969). In addition, patients underwent diagnostic neuroimaging procedures (head computed tomography or magnetic resonance imaging (MRI)) and laboratory testing to rule out other causes of dementia. Patients were excluded from the study if there was clinical evidence of reversible dementias, including pseudo-dementia of depression (all patients had GDS score lower than 14), and presence of concomitant extra-pyramidal signs on exam. In particular, 
patients with strong fluctuations in standard cognitive performance (McKeith et al., 1996; Briel et al., 1999; Barber et al., 2000), which suggest a possible Lewy body dementia or patients showing features of mixed dementia such as Alzheimer and vascular diseases, were excluded from the study.

Diagnosis of AD was made according to NINCDSADRDA (McKhann et al., 1984) and DSM-IV criteria, while VaD was diagnosed according to NINDS-AIREN criteria (Roman et al., 1993). VaD patients had Hachinski Ischemic scores $\geq 4$ (Rosen et al., 1980). All VaD patients underwent brain MRI scanning, in order to select only cases with widespread subcortical vascular involvement. VaD patients with large vessel disease and cortical strokes were excluded, because of the high anatomical variability of the lesions. Additionally, in order to select mild cases, both AD and $\mathrm{VaD}$ patients had a MMSE ranging between 24 and 17. Antidepressant and/or anxiolytic medications were held 24-48 $\mathrm{h}$ prior to EEG recordings (10 $\mathrm{AD}$ and one $\mathrm{VaD}$ subjects). Four $\mathrm{AD}$ subjects were routinely taking stable doses of AChE inhibitors at the time of the study. Since the removal of this small sub-group of treated patients did not change the results, they were included in the final statistics.

Nold subjects were recruited mainly among patients' spouses. They were people over 60 years of age who presented no cognitive impairment as revealed by standard neuropsychological testing for mild cognitive impairment. All normal controls underwent physical and neurological examinations, as well as cognitive screening (including MMSE and GDS). Subjects with present or previous history of neurological or psychiatric disease, chronic systemic illnesses, (e.g. diabetes mellitus or cardiac, hepatic or renal insufficiency), and all subjects receiving psychoactive drugs were excluded from the study. GDS score had to be lower than 14 , in order to exclude potentially depressed individuals.

Table 1 reports the mean values of demographic and clinical characteristics of patients and controls. Sixty mild AD cases, $20 \mathrm{VaD}$ cases, and 30 Nold subjects were studied after the identification of IAF and TF with a spectral profilebased procedure. Women were overrepresented in the AD

\section{Table 1}

Mean values of demographic and neuropsychological characteristics in normal elderly (Nold), mild Alzheimer's disease (AD), and vascular dementia $(\mathrm{VaD})$ subjects

\begin{tabular}{llll}
\hline & Nold & AD & VaD \\
\hline Number & 30 & 60 & 20 \\
Age (years) & $70.70( \pm 1.2 \mathrm{SE})$ & $73.25( \pm 1.03 \mathrm{SE})$ & $75.00( \pm 1.07 \mathrm{SE})$ \\
Gender & $16 / 14$ & $46 / 14$ & $9 / 11$ \\
$\begin{array}{l}\text { (F/M) } \\
\text { MMSE }\end{array}$ & $29.09( \pm 0.23 \mathrm{SE})$ & $20.58( \pm 0.28 \mathrm{SE})$ & $19.58( \pm 1.15 \mathrm{SE})$ \\
$\begin{array}{l}\text { Education } \\
\text { (years })\end{array}$ & $8.60( \pm 0.77 \mathrm{SE})$ & $5.70( \pm 0.54 \mathrm{SE})$ & $9.50( \pm 0.99 \mathrm{SE})$ \\
\hline
\end{tabular}

SE, standard error. group, as expected. Since there are no known genderspecific differences in EEG rhythms, it was felt that this would not interfere with our results. There were no statistical differences in MMSE scores between mild AD and $\mathrm{VaD}$ patients, as revealed by $\operatorname{ANOVA}(P>0.05)$. Age and education were entered as covariates in all statistical analysis to avoid possible confounding effects.

\subsection{EEG recordings}

Specialized clinical units recorded all EEGs. Recordings were obtained with subjects resting comfortably, with their eyes closed. Vigilance was continuously monitored in order to avoid drowsiness. EEG data were recorded $(0.3-70 \mathrm{~Hz}$ bandpass) from 19 electrodes positioned according to the International 10-20 system (Fp1, Fp2, F7, F3, Fz, F4, F8, T3, C3, Cz, C4, T4, T5, P3, Pz, P4, T6, O1, O2), with linked-earlobes reference (subsequently recomputed to common average). A simultaneous electrooculogram $(0.3-70 \mathrm{~Hz}$ bandpass) was also recorded. All data were digitized in continuous recording mode (5 min of EEG; 128-256 Hz sampling rate).

EEG data were analyzed and fragmented off-line in consecutive epochs of $1 \mathrm{~s}$. For standardization purposes, preliminary analysis of all data was centralized at the EEG laboratories of the Department of Human Physiology and Pharmacology (Rome). The EEG epochs with ocular, muscular and other types of artifact were preliminary identified by a computerized automatic procedure (Moretti et al., 2003). Two expert electroencephalographists manually double-checked and confirmed the automatic selections. The EEG epochs contaminated by ocular artifacts were corrected by a standard autoregressive method (Moretti et al., 2003). The EEG epochs in which the ocular artifacts could not be removed with that procedure were rejected from the analysis.

\subsection{Analysis of individual frequency bands}

A digital FFT-based power spectrum analysis (Welch technique, Hanning windowing function, no phase shift) computed the power density of EEG rhythms with a $1 \mathrm{~Hz}$ frequency resolution, ranging from 2 to $40 \mathrm{~Hz}$.

Fig. 1 shows the model of a typical individual EEG spectral profile, averaged across all recording electrodes. Two anchor frequencies were selected according to literature guidelines (Klimesch, 1999), which are the transition theta/alpha frequency (TF) and the individual alpha frequency (IAF) peak. As previously mentioned, the TF marks the transition frequency between theta and alpha bands and it represents an estimate of theta frequency the frequency at which theta and alpha spectra intersect. We computed the TF as the minimum power in the theta frequency range since our EEG recordings were performed at rest. Indeed, there is another method to compute the TF if a task is performed during the EEG recording. In this case, 
TYPICAL EEG/MEG POWER DENSITY SPECTRUM

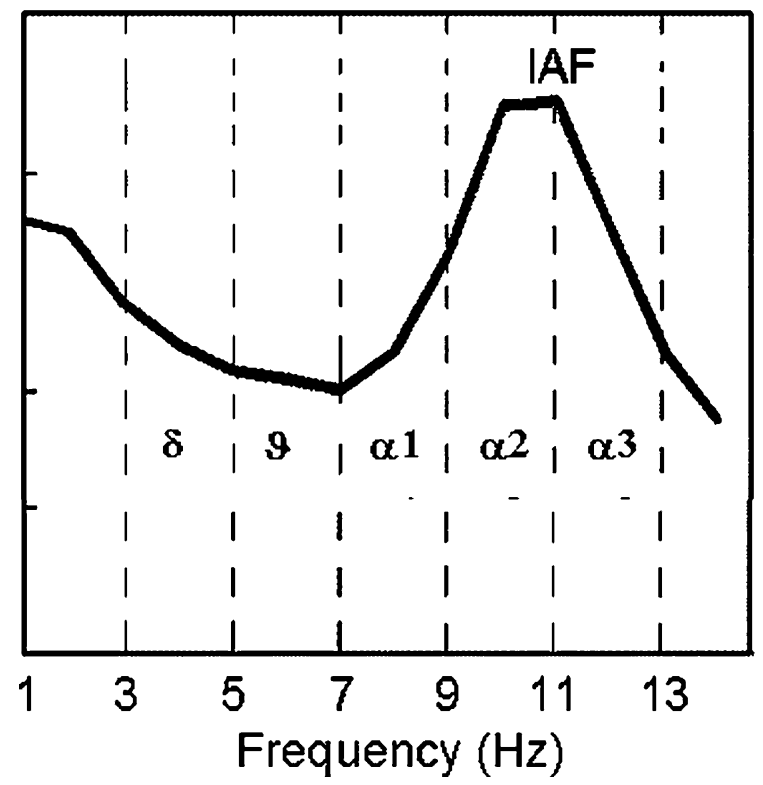

Fig. 1. Scheme illustrating the typical EEG spectral profile of a normal subject. Note the individual alpha frequency (IAF) peak, the transition theta/alpha frequency (TF), and the frequency bands individually determined.

TF is the intersection point of two different power spectra, obtained one for a resting period and the other during task performance.

The IAF represents instead the frequency with the power peak within the extended alpha range $(5-14 \mathrm{~Hz})$. The TF and IAF could be clearly identified in 60 mild AD patients, $20 \mathrm{VaD}$ patients, and 30 Nold subjects, whose EEG data were then statistically analyzed.

Based on the TF and IAF we estimated for each subject the frequency band range as follows: delta from TF-4 to TF-2, theta from TF-2 to TF, low alpha (alpha1 and alpha2) from TF to IAF and high alpha band (or alpha3) from IAF to $\mathrm{IAF}+2$. We introduced a slight variation in the estimation of alpha1 and alpha2 band range respect to the Klimesch method. According to Klimesch, alpha1 ranges from IAF-4 (or TF frequency) to IAF-2 and alpha2 band from IAF-2 to IAF. This computation had the risk of an overlapping between theta and alpha if the distance from IAF and TF is less than $4 \mathrm{~Hz}$. On the other hand, if the distance is more than $4 \mathrm{~Hz}$ there is the risk to leave some portions of the spectrum uncovered. It is of note that in demented subjects we found a great variability in the IAF-TF distance if compared with our normal elderly and with the mean normative values from Klimesch's work. Thus, we computed for each subject alpha1 and alpha 2 band as follows: alpha1 from TF to the middle point of the TF-IAF range and alpha 2 from this middle point to IAF peak. No variation was introduced in the computation of the other frequency bands. Finally, in the frequency bands so determined we computed the relative power spectra for each subject. The relative power density for each frequency band was computed as the ratio between the absolute power and the mean power spectra from 2 to $40 \mathrm{~Hz}$. The relative band power at each band was defined as the mean of the relative band power for each frequency bins within that band.

\subsection{Statistical analysis}

For the statistical comparison of the frequency and the relative power of EEG rhythms, analysis of variance was carried out using education and age as covariates (ANCOVA). Duncan's test was used for post hoc comparisons $(P<0.05)$. The ANCOVA addressed the 'slowing' of the TF and IAF using the frequency values as a dependent variable and the Group factor (AD, VaD, Nold) as the independent variables. For the analysis of the EEG relative power, the ANCOVA used the factors Groups (AD, $\mathrm{VaD}$, Nold) and Frequency band (delta, theta, alpha1, alpha2, alpha3). Moreover, the correlations between MMSE scores and all the EEG indexes were computed in the whole group of 80 demented subjects (VaD plus $\mathrm{AD}$ ) as well as in each of the two groups separately. The MMSE score was correlated with frequencies (TF and IAF) and relative band power (delta, theta, alpha1, alpha2, alpha3) using Pearson's coefficient.

\section{Results}

Fig. 2 shows the superimposition of individual collapsed power spectra of the $\mathrm{AD}, \mathrm{VaD}$, and Nold subjects who were included in the statistical analysis. The TF and IAF are clearly recognized in all groups.

Fig. 3 plots the mean and standard error of the TF and IAF for Nold, AD, and $\mathrm{VaD}$. These values were as follows: $\mathrm{TF}=5.4 \mathrm{~Hz}( \pm 0.8 \mathrm{SE})$ and $\mathrm{IAF}=9.1 \mathrm{~Hz}( \pm 1.1)$ for Nold, TF $=5.3 \mathrm{~Hz}( \pm 1.07)$ and IAF $=8.7 \mathrm{~Hz}( \pm 1.3)$ for $\mathrm{AD}, \mathrm{TF}=4.75 \mathrm{~Hz}( \pm 0.1)$ and $\mathrm{IAF}=8.3 \mathrm{~Hz}( \pm 1.4)$ for $\mathrm{VaD}$ subjects. It should be noted that the low alpha bandwidth of the AD group was slightly narrower than the Nold $(0.3 \mathrm{~Hz})$ and $\mathrm{VaD}(0.25)$ groups, whereas Nold and $\mathrm{VaD}$ groups had practically the same low alpha bandwidth.

ANCOVA was performed pooling both TF and IAF since they are indexes of alpha frequency. ANCOVA showed a trend toward a statistically significant difference in the mean effect of the Group factor $(F(2,105)=2.64 ; P=0.07)$. The greater 'slowing' of alpha frequency was observed in $\mathrm{VaD}$ as compared to both Nold $(P=0.004)$ and $\mathrm{AD}(P=0.04)$ subjects.

Individual frequency bands were selected on the basis of the TF and IAF, and the corresponding relative power density was computed in collapsed spectra. The ANCOVA analysis (Fig. 4) of these values showed a significant interaction between Group factor and Band $(F(8,428)=4.87 ; P<0.00001)$. Duncan post hoc testing 

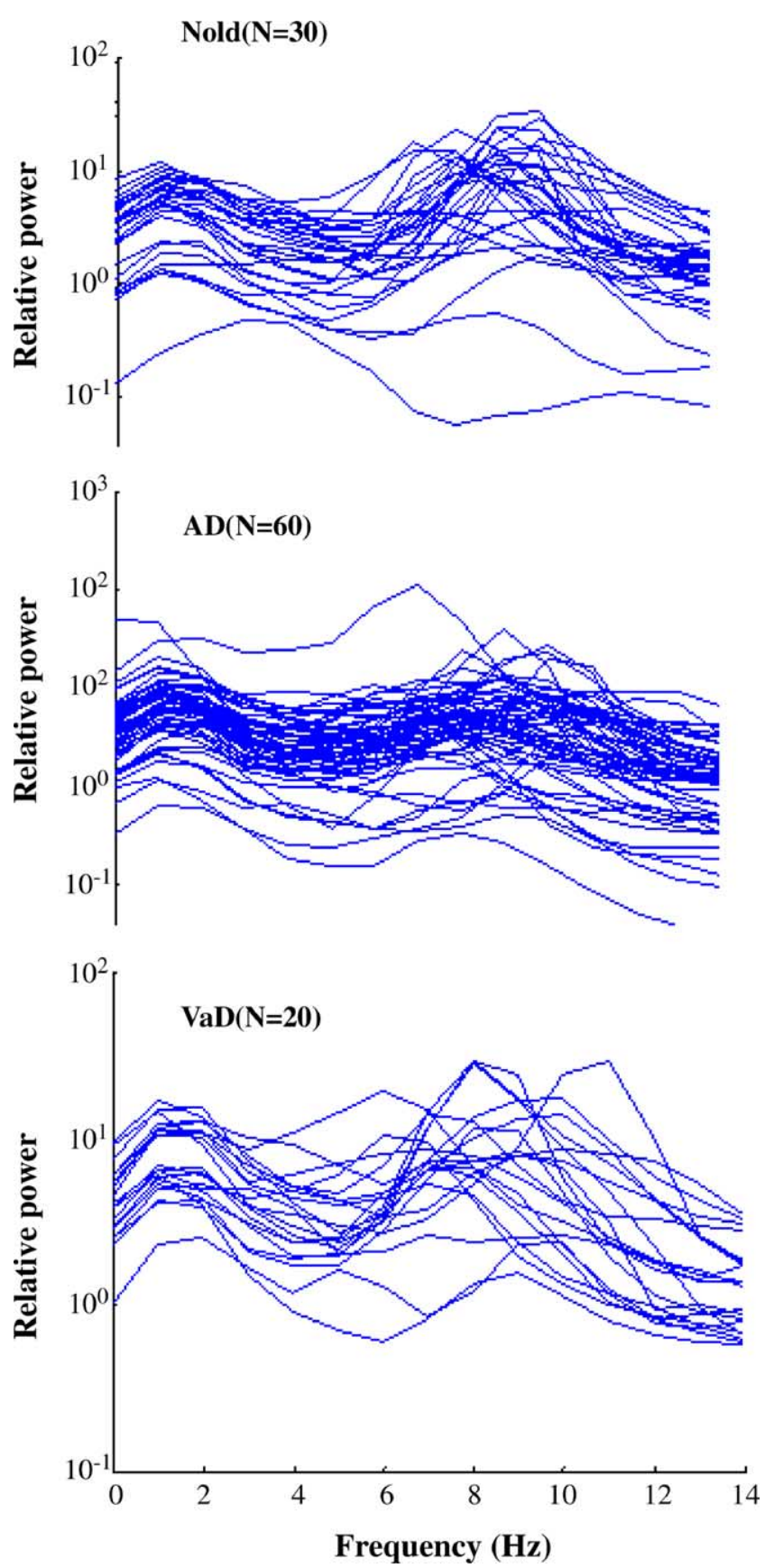

Fig. 2. Diagrams of superimposed individual EEG power spectral profile for the study subjects (Nold, mild $\mathrm{AD}$ and $\mathrm{VaD}$ groups). The EEG power spectral profile of each subject is derived form the average of the EEG power spectral profiles at all recording electrodes. The TF and IAF are clearly visible in individual EEG power spectral profiles.

showed a strong decrease in the relative power of low alpha (alpha2) in AD cases as compared to both Nold $(P<0.00002)$ and $\mathrm{VaD}$ patients $(P<0.03)$, and of high alpha (alpha3) as compared to $\mathrm{VaD}$ patients $(P<0.05)$. Furthermore, the delta relative power was greater in both $\mathrm{AD}$ and $\mathrm{VaD}$ patients compared to Nold subjects $(P=0.05)$, while theta power increased only in $\mathrm{VaD}$ as compared to Nold $(P=0.05)$.

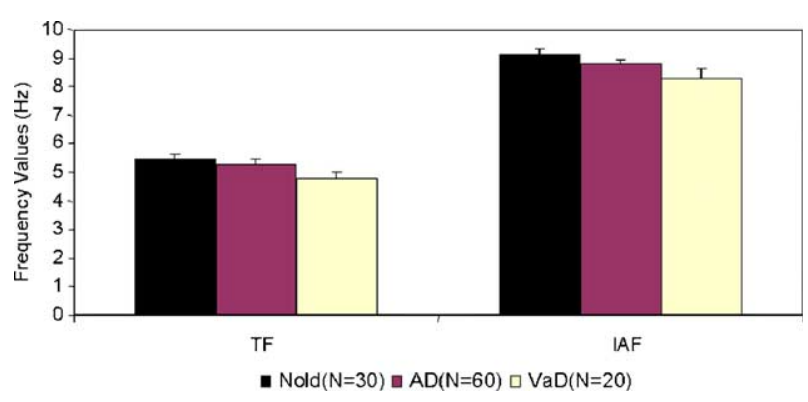

Fig. 3. Diagrams of the mean and standard error of the TF and IAF for Nold, $\mathrm{AD}$, and $\mathrm{VaD}$ groups.

The correlations between the MMSE score and all EEG indexes were computed for all demented patients considered as a group, as well as for each of the two groups. None of these correlations was significant at the $P<0.05$ level.

\section{Discussion}

\subsection{Relative power and frequency of alpha rhythms in mild dementia}

In this study we found that, compared to normal elderly subjects, $\mathrm{VaD}$ patients showed a trend toward a significant 'slowing' of the alpha frequency in both the beginning (TF) and the peak of alpha band (IAF). Moreover, $\mathrm{VaD}$ patients showed a substantial change in alpha power only in alpha2 band. The mild AD patients were characterized instead, by a significant reduction of the individual alpha power in both alpha 2 and alpha3 bands without a substantial slowing of alpha frequency. Finally, relative delta power increased in both $\mathrm{AD}$ and $\mathrm{VaD}$ patients while theta power increased only

\section{STATISTICAL INTERACTION OF GROUP AND BAND}

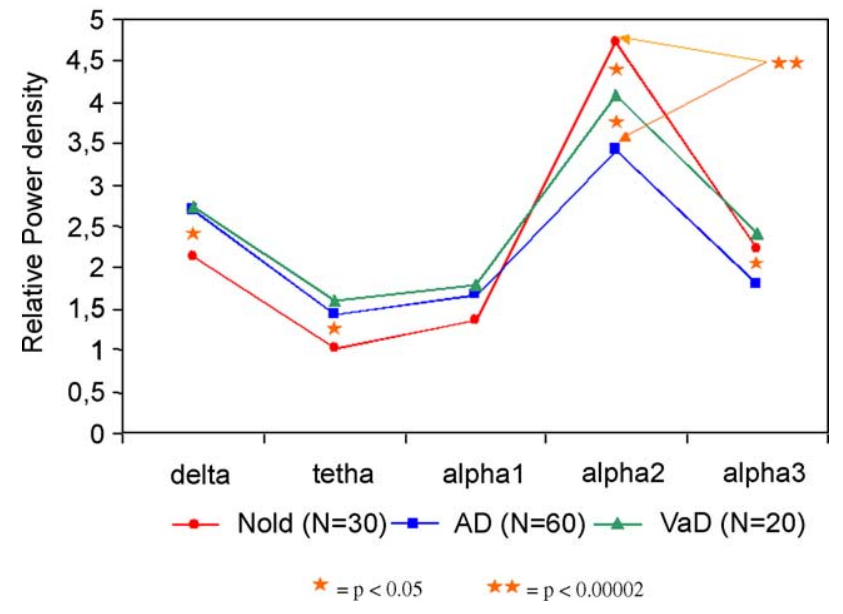

Fig. 4. Statistical ANOVA interaction $(F(8,364)=4.19 ; \mathrm{MSe}=4.023$; $P<0.0001$ ) among Groups factor (Nold, mild AD, $\mathrm{VaD}$ ) and relative band power (delta, theta, alpha1, alpha2, alpha3). The star indicates the significant differences among groups based on Duncan post hoc testing. 
in $\mathrm{VaD}$ patients. We found that the low alpha bandwidth in the AD group was slightly narrower than both Nold $(0.3 \mathrm{~Hz})$ and $\mathrm{VaD}(0.25 \mathrm{~Hz})$ groups. This result merits to be discussed since previous studies (Jonkmann et al., 1992; Salansky et al., 1998) have demonstrated that small differences $(0.3 \mathrm{~Hz})$ in the EEG bandwidth could affect the estimation of band power magnitude. However, it should be remarked that in the present study the low alpha band was divided in two sub-bands (alpha1 and alpha2), so that the mean difference of the alpha sub-band widths in the normal and $\mathrm{AD}$ subjects were practically negligible, i.e. $0.15 \mathrm{~Hz}$ for each alpha sub-band width. Furthermore, the band power was computed as the mean but not the sum of the power frequency bins within that band. Therefore, the bandwidth per se could not affect the estimation of the band power.

It should be noted that the evaluation of absolute power band values could have given different results compared to those obtained considering relative power band values. According to extant literature, we preferred the analysis of the relative power band values, which are not affected by the influences of amplitude of EEG depending on electrical properties of head volume conductor. Furthermore, relative power band values present a lower group variability than absolute power band values do. The use of relative band power values has been recommended in previous influential EEG studies in dementia (Nuwer, 1988; Rodriguez et al., 1999; Leuchter et al., 1993).

The results of our study seem to emphasize a different role for the cholinergic systems and cortico-cortical connections (mainly impaired in mild AD) and the cerebral white matter (mainly damaged in our $\mathrm{VaD}$ ) in regulating the frequency and power of the alpha rhythm. Moreover, they would put into question the classical notion of an inverse relationship between frequency and power of the alpha rhythm, i.e. the higher the amplitude of the alpha rhythm, the slower the frequency of the alpha power peak. The reduction of the alpha power in mild $\mathrm{AD}$ patients, in fact, was not associated with a proportional change of the alpha frequency, whereas slowing of the alpha frequency in $\mathrm{VaD}$ patients was not associated with a proportional change of the alpha power. In this respect, the present findings should be considered with extreme caution, since the inverse relationship of power and frequency is usually applied to the entire spectral range of EEG oscillations. Instead, the effects of the dementia process on the alpha rhythmicity did not involve all alpha sub-bands in the same manner.

The present results confirm previous evidence (Leuchter et al., 1993; Besthorn et al., 1997; Rodriguez et al., 1999) that the cholinergic and intracortical deficits of $\mathrm{AD}$ mainly impair synchronization mechanisms at the basis of the resting alpha power, which is modulated by cortico-cortical and cortico-thalamo-cortical interactions (Steriade and Llinas, 1988; Pfurtscheller and Lopes da Silva, 1999; Nunez et al., 2001). Based on the determination of individual EEG sub-bands, the power reduction in $\mathrm{AD}$ was noted to occur at the low (about 8-10 Hz) and high alpha bands (about 10-12 Hz). From a functional point of view, the low- alpha band power $(8-10 \mathrm{~Hz})$ could relate to attentional systems, in contrast to the high- alpha band power $(10-12 \mathrm{~Hz})$ that reflects processing of task-specific sensorimotor or semantic information (Klimesch, 1999). Therefore, the reduction of the alpha band power in mild $\mathrm{AD}$ can be explained in terms of an abnormal increase of cortical excitation or disinhibition during the resting state. This possible explanation is in line with previous evidence of abnormal central EEG rhythms or evoked potentials in AD subjects performing voluntary movements or perceiving somatosensory stimuli (Babiloni et al., 2000; Ferri et al., 1996). Furthermore, abnormally hyperexcitable primary motor cortex has been recently reported in $\mathrm{AD}$, as revealed by EEG rhythms related to self-paced movements and transcranial magnetic stimulation (Babiloni et al., 2000; Pennisi et al., 2002; Ferreri et al., 2003;).

In this study, $\mathrm{VaD}$ patients with diffuse vascular lesions of the white matter, showed slowing of the alpha frequency with a decrement of the band power only in low alpha range. A previous study (d'Onofrio et al., 1996) has shown a slowing in the beginning of alpha frequency in vascular demented subjects that fits our findings, although the mentioned study was carried out using fixed but not individual frequency bands. Furthermore, these results are in line with previous evidence showing that lesions of the white matter in $\mathrm{VaD}$ were directly related to a widespread slowing of EEG rhythmicity (Szelies et al., 1992, 1999). The white matter lesions of multiple sclerosis also decreased the frequency of the alpha rhythm (Leocani et al., 2000), while successful immunosuppressive treatment, probably restoring appropriate nerve propagation, resulted in recovery of normal alpha frequency without effects on the relative power (Colon et al., 1981). Finally, tumors of the cerebral white matter, but not of the gray matter, decrease the frequency of the alpha rhythm (Gloor et al., 1968; Goldensohn, 1979).

A reasonable explanation of the present results is that the slowing of the alpha frequency in $\mathrm{VaD}$ could be mainly ascribed to impairment of the bidirectional connectivity along cortico-thalamo-cortical fibers. Such impairment could slow the conduction time of the action potentials throughout the cortico-thalamo-cortical pathways (Tomasch, 1954; Steriade and Llinas, 1988; Pfurtscheller and Lopes da Silva, 1999), interfering with the inhibitory control of the reciprocal cortico-thalamo-cortical modulations (Sarter and Bruno, 1997; Destexhe et al., 1998; Doiron et al., 2003). Computational models have previously shown that the EEG frequency relies on axonal delay and synaptic time of the cortico-thalamo-cortical interactions as well as on the activity of inhibitory reticulo-thalamic neurons (Lopes da Silva et al., 1976; Nunez et al., 2001; Doiron et al., 2003). Additionally, the prevalence of the white matter damage could not exclude an impairment of the gray matter, even though less evident than in $\mathrm{AD}$ patients. Moreover, definitive conclusions in vascular 
demented patients could be drawn in future studies recruiting a larger group size.

Taken together, our data suggest that the regulation of the alpha power during wakeful rest is related to the full integrity of the cholinergic systems and cortico-cortical connections (mainly impaired in mild AD) more than to integrity of the white matter (mainly damaged in $\mathrm{VaD}$ patients). The cholinergic systems are essential for the control of selective attention (Sarter and Bruno, 1997, 1999, 2000) and are mainly represented by two projection systems directly affecting the cortex. The first projection system connects basal forebrain structures to the cortex and the thalamus, while the second projection system connects the rostral brainstem (pedunculopontine and lateral dorsal tegmentum) to the cortex via the thalamus (Kobayashi and Tadashi, 2002). At rest, the afferent cholinergic inputs of these projection systems would synchronize long-range cortico-cortical connections that are also affected in AD due to loss of dendritic spines, neurons and to beta-amyloid plaque deposition. Accordingly, these cholinergic inputs would sustain the power of the alpha rhythm (Holschneider et al., 1998; Villa et al., 2000). This explanation agrees with the reduction of functional cortico-cortical coupling, revealed by EEG coherence studies, in $\mathrm{AD}$ patients compared to normal controls (Leocani et al., 2000) and VaD patients (Leuchter et al., 1992). The regulation of the alpha frequency would otherwise be relatively independent of the full integrity of the cholinergic systems and corticocortical connections (mainly impaired in mild AD). Rather, it would mainly depend on the integrity of the white matter (mainly damaged in VaD). As a speculation, the present findings suggest that mild AD may have no major damage of the white matter and a relatively spared transmission of inhibitory cortico-thalamo-cortical inputs modulating the alpha frequency.

\subsection{Low EEG rhythms in mild dementia}

Compared to the normative data, the landmark of the slow EEG frequency (TF) was slowed by $\mathrm{VaD}$ but not by mild AD subjects. Mild dementia affected the power of the EEG slow rhythms more than frequency. Namely, the magnitude of the delta power was greater in $\mathrm{VaD}$ and $\mathrm{AD}$ patients than in Nold subjects, as if it depended on nonspecific effects of dementia. These findings agree with previous reports in which white matter lesions in mild $\mathrm{VaD}$ induced a large and widespread increase of the slow EEG power (Gloor et al., 1968; Coben et al., 1983), correlated with a reduction in regional cerebral metabolism (Szelies et al., 1999). The present findings also agree with previous studies in $\mathrm{AD}$ demonstrating an increase in slow EEG rhythms together with a reduction of regional cerebral blood flow (Rae-Grant et al., 1987; Stigsby et al., 1981; Brenner et al., 1986; Nobili et al., 1999).

Theta frequency increased only in $\mathrm{VaD}$ subjects so it might represent an earlier index of vascular dementia.
The present findings agree with previous studies in which subcortical damage in mild $\mathrm{VaD}$ patients were responsible for a large and widespread increase of theta source activity (Gloor et al., 1977; Coben et al., 1983). Of note, the increase of theta could be linked to the general slowing of the dominant frequency in $\mathrm{VaD}$ and this could explain why it is less evident in mild AD. On the other hand, it could be possible that in AD theta band is not yet impaired in a very early stage of disease, but its impairment could be expressed later.

Converging evidence from the relevant literature indicates that the power of the slow EEG rhythms may represent a global state of cortical deafferentation due to various anatomo-functional substrates including cholinergic projections (impaired in mild AD) and white matter (impaired in our VaD patients). This slow oscillatory mode of the brain would prevent an efficient processing of internal or external stimuli, as it may occur during deep stages of sleep, which are characterized by high-power low frequency EEG rhythms. According to previous suggestions (Llinas et al., 1999), a pathological increase of slow EEG power might rely on a cortico-thalamo-cortical dysrhythmia involving the non-specific thalamic system. Of note, this system must not be confused with the brain network modulating a narrow EEG slow band (theta) during cognitive efforts, which is induced upon frontomedial/cingulate areas by (para)hippocampal formation (Klimesch, 1999). In the present protocol (resting EEG), this issue could not be addressed.

\subsection{Correlation between EEG and MMSE}

The correlations between the MMSE score and all EEG indices were not significant in either the demented patients considered as a group or in each group. This was apparently at variance with previous studies (Rodriguez et al., 1999; Matousek et al., 2001) showing significant correlations of MMSE score with EEG frequency and band power. However, it should be remarked that in the mentioned studies the correlations between MMSE and EEG parameters were observed mainly at circumscribed temporoparietal scalp regions. Therefore, it is possible that the lack of correlations between the MMSE score and the present EEG indices was due to averaging of the spectral parameters across electrodes of the whole scalp. This explanation is consistent with recent evidence showing no correlation between MMSE score and EEG parameters (2-14 Hz) collapsed across all sensors (Stam, 2000; Stam et al., 2002, 2003). It can be concluded that the averaging of EEG indices across all electrodes is useful for data reduction purposes but it can mask some correlations with mental functions localized in specific brain areas.

\section{Conclusions}

The present EEG study investigated the respective role of the cholinergic system and cortico-cortical connections 
(impaired in mild AD), and the sub-cortical white matter (lesioned in $\mathrm{VaD}$ ) on the relationship between individual EEG frequencies and their relative power bands.

Compared to normal elderly subjects, $\mathrm{VaD}$ patients showed a significant 'slowing' of the alpha frequency not associated with a proportional change in the alpha band power. On the other hand, the AD patients' EEGs were characterized by a significant reduction of the alpha power not associated with a substantial change in alpha frequency.

Finally, the relative delta power increased in both AD and $\mathrm{VaD}$ patients while theta power increased only in $\mathrm{VaD}$ subjects. These results put into question the classical inverse relationship between the frequency and power in normal EEG rhythms and emphasize the differential role of specific abnormalities in these two forms of dementia in the regulation of the frequency and power of alpha rhythms. Furthermore, they suggest that individual analysis of alpha frequency and power could discriminate mild $\mathrm{AD}$ from $\mathrm{VaD}$ and normal elderly subjects. Future investigations are needed to validate the clinical usefulness of these findings in early differential diagnosis, disease staging, and therapy monitoring.

The results of the present study will be made available at the WEB site of the present multi-centric study (http:// hreeg.ifu.uniroma1.it/Alzheimer.htm).

\section{Acknowledgements}

We thank Dr. Fabio Babiloni, Mrs. Gabriella Busonero, Dr. Paola Chiovenda, Dr. Filippo Carducci, Dr. Febo Cincotti, Mrs. Matilde Ercolani, Mrs. Rita Fini, Dr. Giovanni Frisoni, Dr. Massimo Gennarelli, Dr. Nicola Girtler, Dr. Katiuscia Sosta, Dr. Franca Tecchio, and Dr. Filippo Zappasodi for their precious help in the development of the present study. We thank also Professor Fabrizio Eusebi for his continuous support. The research was granted by Foundation Telethon Onlus (project EC0985).

\section{References}

Babiloni C, Babiloni F, Carducci F, Cincotti F, DDel Percio C, DDe Pino G, Maestrini S, Priori A, Tisei P, Zanetti O, Rossini PM. Movementrelated electroencephalographic reactivity in Alzheimer disease. Neuroimage 2000;12(2):139-46.

Barber PA, Varma AR, Lloyd JJ, Haworth B, Snowden JS, Neary D. The electroencephalogram in dements with Lewy bodies. Acta Neurol Scand 2000;101:53-6.

Bennys K, Rondouin G, Vergnes C, Touchon J. Diagnostic value of quantitative EEG in Alzheimer's disease. Neurophysiol Clin 2001;31: $153-60$.

Besthorn C, Zerfass R, Geiger-Kabisch C, Sattel H, Daniel S, SchreiterGasser U, Forstl H. Discrimination of Alzheimer's disease and normal aging by EEG data. Electroenceph clin Neurophysiol 1997;103(2): $241-8$.
Brenner RP, Ulrich RF, Spiker DG, Sclabassi RJ, Reynolds III CF, Mrin RS, Boller F. Computerized EEG spectral analysis in elderly normal, demented and depressed subjects. Electroenceph clin Neurophysiol 1986;64:483-92.

Briel RCG, McKeith LG, Barker WA, Hewitt Y, Perry RH, Incew PG, Fairbairn AF. EEG findings in dementia with Lewy bodies and Alzheimer's disease. J Neurol Neurosurg Psychiatry 1999;66:401-3.

Chiaramonti R, Muscas GC, Paganini M, Muller TJ, Fallgatter AJ, Versari A, Strik WK. Correlations of topographical EEG features with clinical severity in mild and moderate dementia of Alzheimer type. Neuropsychobiology 1997;36(3):153-8.

Coben LA, Danziger W, Storandt M. A longitudinal EEG study of mild dementia of Alzheimer type: changes at 1 year and 2.5 years. Electroenceph clin Neurophysiol 1983;55:372-80.

Coben LA, Chi D, Snyder AZ, Storandt M. Replication of a study of frequency analysis of the resting awake EEG in mild probable Alzheimer's type. Electroenceph clin Neurophysiol 1990;75:148-54.

Colon E, Hommes OR, de Weerd JP. Relationship between EEG and disability scores in multiple sclerosis. Clin Neurol Neurosurg 1981;83: $163-8$.

Destexhe A, Sejnowski TJ. Synchronized oscillations in thalamic networks: insight from modeling studies. In: Steriade M, Jones EG, McCormick DA, editors. Thalamus. Amsterdam: Elsevier; 1996.

Destexhe A, Contreras D, Steriade M. Mechanism underlying the synchronizing action of corticothalamic feedback inhibition of thalamic relay cells. J Neurophysiol 1998;79:999-1016.

d'Onofrio S, Salvia S, Petretta V, Bonavita V, Rodriguez G, Tedeschi G. Quantified-EEG in normal aging and dementias. Acta Neurol Scand 1996;93(5):336-45.

Doiron B, Chacron MJ, Maler L, Longtin L, Bastian J. Inhibitory feedback required for network oscillatory responses to communication but not prey stimuli. Nature 2003;421:538-43.

Elul R. The genesis of EEG. Int Rev Neurobiol 1972;15:227-72.

Ferreri F, Pauri F, Pasqualetti P, Fini F, Dal Forno G, Rossini PM. Motor cortex excitability in Alzheimer's Disease: a transcranial magnetic stimulation study. Ann Neurol 2003;53(1):102-8.

Ferri R, Del Gracco S, Elia M, Musumeci SA, Spada R, Stefanini MC. Scalp topographic mapping of middle-latency somatosensory evoked potentials in normal aging and dementia. Neurophysiol Clin 1996; 26(5):311-9.

Folstein MF, Folstein SE, McHugh PR. 'Mini Mental State12:189-98.

Gloor R, Kalabay O, Giard N. The electroencephalogram in diffuse encephalopathies. Electroencephalographic correlates of gray and white matter lesions. Brain 1968;91:779-802.

Gloor P, Ball G, Schaul N. Brain lesions that produce delta waves in the EEG. Neurology 1977;27(4):326-33.

Goldensohn ES. Use of EEG for evaluation of focal intracranial lesions. In: Klass DW, Daly DD, editors. Current practice of clinical electroencephalography. New York: Raven; 1979. p. 307-41.

Gueguen B, Derouesne C, Bourdel MC, Guillou S, Landre E, Gaches J, Hossard H, Ancri D, Mann M. Apport de l'EEG quantifiee au diagnostic de demence de type Alzheimer. Neurophysiol Clin 1991;21:357-71.

Holschneider DP, Leuchter AF, Scremin OU, Treiman DM, Walton NW. Effects of cholinergic deafferentation and NGF on brain electrical coherence. Brain Res Bull 1998;45:531-41.

Hughes CP, Berg L, Danziger WL, Cohen LA, Martin RL. A new clinical rating scale for the staging of dementia. Br J Psychiatry 1982;140: 1225-30.

Jonkmann E, De Weend A, Poortvliet DCJ. EEG studies in workers exposed to solvents or pesticides. Electroenceph clin Neurophysiol 1992;82:438-44.

Ihl R, Dierks T, Martin EM, Frolich L, Maurer K. Topography of the maximun of the amplitude of EEG frequency in dementia of the Alzheimer type. Biol Psychiatry 1996;39:319-25.

Klimesch W. EEG alpha and theta oscillations reflect cognitive and memory performance: a review and analysis. Brain Res Rev 1999;29: 169-95. 
Kobayashi Y, Tadashi I. Sensory-motor gating and cognitive control by the brainstem cholinergic system. Neural Networks 2002;731-41.

Kopruner V, Pfurtscheller G, Auer LM. Quantitative EEG in normals and in patients with cerebral ischemia. In: Pfurtscheller G, Jonkman EJ, Lopes da Silva FH, editors. Brain ischemia: quantitative EEG and imaging techniques. Progress in brain research, vol. 62. Amsterdam: Elsevier; 1984. p. 29-50

Lawton MP, Brodie EM. Assessment of older people: self maintaining and instrumental activity of daily living. J Gerontol 1969;9:179-86.

Leocani L, Locatelli T, Martinelli V, Rovaris M, Falautano M, Filippi M, Magnani G, Comi G. Electroencephalographic coherence analysis in multiple sclerosis: correlation with clinical, neuropsychological, and MRI findings. J Neurol Neurosurg Psychiatry 2000; 69:192-8

Leuchter AF, Newton TF, Cook IA, Walter DO, Rosenberg-Thompson S, Lachenbruch PA. Changes in brain functional connectivity in Alzheimer-type and multi-infarctual dementia. Brain 1992;115: 1543-61.

Leuchter AF, Cook IA, Newton TF, Dunkin J, Walter DO, RosenbergThompson S, Lachenbruch PA, Weiner H. Regional differences in brain electrical activity in dementia: use of spectral power and spectral ratio measures. Electroenceph clin Neurophysiol 1993;87:385-93.

Llinas RR, Ribary U, Jeanmonod D, Kronberg E, Mitra PP. Thalamocortical dysrhythmia: a neurological and neuropsychiatric syndrome characterized by magnetoencephalography. Proc Natl Acad Sci USA 1999;96(26):15222-7.

Lopes da Silva FH, van Rotterdam A, Barts P, van Heusden E, Burr W. Models of neuronal populations: the basic mechanism of rhythmicity. In: Corner MA, Swaab DF, editors. Perspectives of brain research. Progress in brain research, vol. 45. Amsterdam: Elsevier; 1976. p. $281-308$

Lopes da Silva FH, Mooibroek J, van Rotterdam A. Relative contribution of intracortical and thalamo-cortical process in the generation of alpha rhythms revealed by partial coherence analysis. Electroenceph clin Neurophysiol 1980;50:449-56.

Maurer K, Dierks T. Functional imaging procedures in dementias: mapping of EEG and evoked potentials. Acta Neurol Scand 1992; 139:40-6.

Matousek M, Brunovsky M, Edman A, Wallin A. EEG abnormalities reflect the parietal lobe syndrome. Clin Neurophysiol 2001;112:1001-5.

McKeith IG, Galasko D, Kosaka K, Perry EK, Dickson DW, Hansen LA. Consensus guidelines for the clinical and pathologic diagnosis of dementia with Lewy bodies (DLB): report of the consortium on DLB international workshop. Neurology 1996;47:1113-24.

McKhann G, Drachman D, Folstein M, Katzman R, Price D, Stadlan EM. Clinical diagnosis of Alzheimer's disease: report of the NINCDSADRDA Work Group under the auspices of Department of Health and Human Services Task Force on Alzheimer's disease. Neurology 1984; 34:939-44.

Moretti DV, Babiloni F, Carducci F, Cincotti F, Remondini E, Rossini PM, Salinari S, Babiloni C. Computerized processing of EEG-EOG-EMG artifacts for multicentirc studies in EEG oscillations and event-related potentials. Int J Pshycophysiol 2003;47(3):199-216.

Niedermayer E. The normal EEG in waking adult. In: Niedermayer E, Lopes da Silva FH, editors. Electroencefalography: basic principles, clinical applications and related fields. Baltimore, MD: Williams and Wilkins; 1993. p. 131-52.

Nobili F, Copello F, Vitali P, Prastaro T, Carozzo S, Perego G, Rodriguez G. Timing of disease progression by quantitative EEG in Alzheimer's patients. J Clin Neurophysiol 1999;16(6):566-73.

Nunez PL, Wingeier BM, Silberstein RB. Spatial-temporal structures of human alpha rhythms: theory, microcurrent sources, multiscale measurement and global binding of local networks. Hum Brain Mapp 2001;13:125-64.

Nuwer MR. Quantitative EEG I: technique and problems of frequency analysis and topographic mapping. J Clin Neurophysiol 1988;5: $1-43$.
Pennisi G, Alagona G, Ferri R, Greco S, Santonocito D, Pappalardo A, Bella R. Motor cortex excitability in Alzheimer disease: one year follow-up study. Neurosci Lett 2002;329(3):293.

Pfurtscheller G, Lopes da Silva F. Event-related EEG/MEG synchronization and desynchronization: basic principles. Clin Neurophysiol 1999; 110:1842-57.

Rae-Grant A, Blume W, Breslau C, Hachinski VC, Fisman M, Merskey H. The electroencephalogram in Alzheimer type dementia.A sequential study correlating the electroencephalogram with psycometric and quantitative pathological data. Arch Neurol 1987;44:50-5.

Rodriguez G, Copello F, Vitali P, Perego G, Nobili F. EEG spectral profile to stage Alzheimer's disease. Clin Neurophysiol 1999;110: $1831-7$.

Roman GC, Tatemichi TK, Erkinjuntti T, Cummings JL, Masdeu JC, Garcia JH, Amaducci L, Orgogozo JM, Brun A, Hofman A, et al. Vascular dementia: diagnostic criteria for research studies. Report of the NINDS-AIREN International Workshop. Neurology 1993;43(2): $250-60$.

Rosen WG, Terry RD, Fuld PA, Katzman R, Peck A. Pathological verification of ischemic score in differentiation of dementias. Ann Neurol 1980;7(5):486-8.

Salansky N, Fedotchev A, Bondar A. Responses of the nervous system to low frequency stimulation and EEG rhythms: clinical implications. Neurosci Biobehav Rev 1998;22:395-409.

Sarter M, Bruno JP. Cognitive functions of cortical cholinergic: toward a unifying hypothesis. Brain Res Rev 1997;23:329-43.

Sarter M, Bruno JP. Abnormal regulation of corticopetal cholinergic neurons and impaired information processing in neuropsychiatric disorders. Trends Neurosci 1999;22:67-74.

Sarter M, Bruno JP. Cortical cholinergic inputs mediating arousal, attentional processing and dreaming: differential afferent regulation of the basal forebrain by telencephalic and brainstem afferents. Neuroscience 2000;95:933-52.

Schreiter-Gasser U, Gasser Th, Ziegler P. Quantitative EEG-analysis in early onset Alzheimer's disease: a controlled study. Electroenceph clin Neurophysiol 1993;86:15-22.

Schreiter-Gasser U, Gasser T, Ziegler P. Quantitative EEG analysis in early onset Alzheimer's disease: correlations with severity, clinical characteristics, visual EEG and CCT. Electroenceph clin Neurophysiol 1994; 90(4):267-72.

Singer W. Synchronization of cortical activity and its putative role in information processing and learning. Annu Rev Physiol 1993;55: $349-74$.

Sloan EP, Fenton GW, Kennedy NSJ, MacLennan JM. Electroencephalography and single photon emission computed tomography in dementia: a comparative study. Psychol Med 1995;25:631-8.

Stam CJ. Brain dynamics in theta and alpha frequency bands and working memory performance in humans. Neurosci Lett 2000;286: $115-8$.

Stam CJ, van Cappellenvan Walsum AM, Pijnenburg YA, Berendse HW, de Munck JC, Scheltens P, van Dijk BW. Generalized synchronization of MEG recordings in Alzheimer's Disease: evidence for the involvement of the gamma band. J Clin Neurophysiol 2002;19(6): $562-74$.

Stam CJ, van der Made Y, Pijnenburg YA, Scheltens P. EEG synchronization in mild cognitive impairment and Alzheimer's disease. Acta Neurol Scand 2003;108(2):90-6.

Steriade M, Llinas RR. The functional states of the thalamus and the associated neuronal interplay. Physiol Rev 1988;68:649-742.

Stigsby B, Johannesson G, Ingvar DH. Regional EEG analysis and regional cerebral blood flow in Alzheimer's and Pick's diseases. Electroenceph clin Neurophysiol 1981;51:537-47.

Suffczynski P, Stilian K, Pfurtscheller G, Lopes da Silva FH. Computational model of thalamo-cortical networks: dynamical control of alpha 
rhythms in relation to focal attention. Int J Psychophysiol 2001;43: $25-40$.

Szelies B, Grond M, Herholz K, Kessler J, Wullen T, Heiss WD. Quantitative EEG mapping and PET in Alzheimer's disease. J Neurol Sci 1992;110:46-56.

Szelies B, Mielke R, Kessler J, Heiss WD. EEG power changes are related with regional cerebral glucose metbolism in vascular dementia. Clin Neurophysiol 1999;110:615-20.
Tomasch J. Size, distribution and number of fibers in the human corpus callosum. Anat Rec 1954;119:119-35.

Villa AEP, Tetko IV, Dutoit P, Vantini G. Non-linear cortico-cortical interactions modulated by cholinergic afferences from the rat basal forebrain. Biosystem 2000;58:219-28.

Yesavage JA, Brink TL, Rose TL, Lum O, Huang V, Adey M, Leirer VO. Development and validation of a geriatric depression screening scale: a preliminary report. J Psychiatry Res 1982;17(1):37-49. 